\title{
Modern trends in container transportation in rail-marine messages of Russia Gagarskiy E. ${ }^{1}$, Kirichenko S. $^{2}$ \\ Современные тенденции контейнерных перевозок в железнодорожно-морских сообщениях России \\ Гагарский Э. А. ${ }^{1}$, Кириченко С. А. ${ }^{2}$
}

\begin{abstract}
${ }^{I}$ Гагарский Энгельс Александрович / Gagarskiy Engels - доктор технических наук, Ph.D., профессор, руководитель, Центр транспортной координации и транспортно-технологических систем;

${ }^{2}$ Кириченко Сергей Алексеевич / Kirichenko Sergey - заведующий сектором контейнерных перевозок, Акционерное общество «Проектно-изыскательский и научно-исследовательский институт морского транспорта Союзморниипроект», г. Москва
\end{abstract}

\begin{abstract}
Аннотация: в статье анализируется современное состояние контейнерной системы России. Изложень основные направления развития контейнерной системь в посткризисный период, перспективные технологии транспортировки грузов в контейнерах.

Abstract: the article analyzes the current state of the container system of Russia. The main directions of development of a container system in the postcrisis period, the perspective technologies of containerized cargoes transportation are stated.
\end{abstract}

Ключевые слова: контейнеризация, интермодальные перевозки, порты.

Keywords: containerization, intermodal transport, ports.

В 2015 году общий объем перевозок российских грузов через морские порты России и сопредельных государств составил 729,2 млн. т., что на 3,1 \% больше, чем в 2014 году. При этом объём перевалки грузов через порты России за 2015 год увеличился значительнее - на 5,7 \% и составил 676,8 млн. т. Соответственно перевалка в портах Украины и стран Балтии сократилась на 18,5 \% и составила 62,4 млн. T.

При в целом положительных результатах деятельности морского транспорта и сохранении роста объемов перевозок, впервые после 2009 года отрасль столкнулась с кризисными явлениями в части контейнерных перевозок морем, перевалка грузов в контейнерах уменьшилась на 14,4 \% до 40,1 млн. т.

Таблица 1. Перегрузки контейнеров через порты России (тыс. m)

\begin{tabular}{|c|c|c|c|c|c|c|c|c|c|c|c|}
\hline $\begin{array}{c}\text { Бассейны } \\
\text { / годы }\end{array}$ & 2005г. & 2006г. & 2007г. & 2008г. & 2009г. & 2010г. & 2011г. & 2012г. & 2013г. & 2014г. & 2015г. \\
\hline $\begin{array}{c}\text { Северозап } \\
\text { адный } \\
\text { бассейн }\end{array}$ & 11103,3 & 16881 & 18977 & 20655 & 15200 & 21319 & 24687 & 26356 & 26473 & 27516 & 23410 \\
\hline $\begin{array}{c}\text { Южный } \\
\text { бассейн }\end{array}$ & 2047,7 & 2743 & 3905 & 3883 & 3350 & 4196 & 5810 & 6172 & 6150 & 6806 & 6410 \\
\hline $\begin{array}{c}\text { Дальнево- } \\
\text { сточный } \\
\text { бассейн }\end{array}$ & 5309,4 & 6337,3 & 7415 & 7534 & 6720 & 7407 & 8903 & 10172 & 11810 & 12466 & 10280 \\
\hline Всего & 18460,4 & 25961,3 & 30297 & 32072 & 25270 & 32900 & 39400 & 42701 & 44423 & 46800 & 40100 \\
\hline
\end{tabular}

С одной стороны, введенные санкции против России, последовавшее ослабление национальной валюты, привели к падению платежеспособности многих российских потребителей и сокращению импорта. Способствовал этому и взятый Правительством России курс на импортозамещение. В результате перевозки импортных грузов в контейнерах сократились за 2015 год почти на треть (на 27.3 \%) с 25,4 млн. т до 18,5 млн. т. (2015 г.). Во многом это результат общей экономической ситуации, в которой вынужден был работать транспорт.

С другой стороны, в экспортном направлении произошел рост контейнерных перевозок на $0,2 \%$ с 15550 до 15580 тыс. т (2015 г.). Это весьма скромный результат, учитывая общий рост объемов экспорта грузов морем. Впервые с момента распада СССР морской транспорт в ряде портов по определенным направлениям столкнулся с проблемой предоставления порожних контейнеров под экспортные грузы. Оговоримся, что такая ситуация была не всегда, не все месяцы года и не во всех портах, но она негативно сказалась на итоговых отраслевых показателях морского транспорта по контейнерным перевозкам.

Традиционно объем импортных перевозок грузов в контейнерах морем превышает объем экспортных перевозок [1]. Поэтому в прошлое десятилетие иностранные судоходные компании с большим желанием предоставляли свои высвобождающиеся контейнеры под загрузку российским экспортом для отправки 
груза на море. Теперь по целому ряду направлений имеется дефицит порожних контейнеров, и грузовладельцы получают отказы на контейнерную экспортную перевозку морем.

В определенной мере сложившаяся ситуация является недоработкой в сфере транспорта, в части взаимодействия железной дороги и морского транспорта [2]. Так, ранее, во времена СССР такой ситуации не могло быть, так как в рамках равночисленного обмена контейнерами (между Минморфлотом и МПС) грузы уходили в море в экспорте в контейнерах собственности МПС [3]. Равночисленный обмен отменен, но до сих пор не предложено какой-либо действенной альтернативы для этой ситуации.

Как недостаток следует отметить, что морской транспорт не располагает в настоящее время собственным контейнерных парком, соответствующим объемам перевозок (хотя отдельные судоходные контейнеры имеют в собственности контейнеры). Широко привлекаются к перевозкам контейнеры иностранных судовладельцев, а также международных контейнерных операторов [4]. В результате механизма, как покрывать локальные дефициты порожних контейнеров для экспорта в отдельных портах, сейчас нет.

Позитивным моментом в сложившейся сложной экономической ситуации следует отметить рост объемов контейнерных перевозок в каботаже на $+3,3$ \%. (Для сопоставления на сети железных дорог РФ контейнерные перевозки во внутреннем сообщении упали.)

Увеличение контейнерных перевозок морем во внутрироссийском сообщении произошло, в основном, за счет возобновления активности России в Арктике, а также за счет контейнеризации части грузопотока грузов в/на Р. Крым [5]. Контейнерные перевозки в Крым увеличились за год более чем в 5 раз с 26,5 тыс. т (2014 г.) до 151 тыс. т (2015 г.).

Однако потенциал роста значителен. Так, перевозки грузов на паромах в Крым как через Керченскую переправу, так и на морских линиях, возросли за год почти в 4,5 раза и достигли 10 млн. тонн. Это обуславливается разрывом связей крымских предприятий с Украиной и все большей интеграцией региона в российское экономическое пространство.

В настоящее время все порты мира перегружают до 500 млн. дфэ/год: в данный показатель включен трансшипмент и порожние контейнеры. Контейнерные перевозки грузов в мире неуклонно растут. Контейнеризация в ряде стран достигла $55 \%$ общего объема контейнеропригодных грузов. По оценке экспертов этот показатель к 2020 г. может составить 60 \%, что свидетельствует о значительной работе, проводимой транспортными, экспедиторскими компаниями, а также грузоотправителями по внедрению прогрессивных технологий [1].

Опираясь на статистические данные и данные компаний-перевозчиков, доля доставки в контейнерах контейнеропригодных грузов в/из России составляет: по экспорту - 6 \%, по импорту - $31 \%$.

На море магистральным направлением снижения энергетических затрат на единицу транспортной продукции (перевозку 1 т груза на 1 морскую милю или на 1 км), а также себестоимости морских перевозок является увеличение грузоподъемности судов. На базе анализа многолетних данных можно утверждать, что при росте грузоподъемности судна в 3 раза удельные затраты сокращаются почти в 2 раза [6].

Однако увеличение грузоподъемности контейнеровозов не может рассматриваться изолировано от других составных элементов транспортно-технологической системы (ТTC). Они должны быть полностью сбалансированы.

Стало уже аксиомой, что крупнотоннажные суда наиболее эффективно работают в рамках соответствующих ТТС - контейнеровозной, блок-пакетовозной, системы сменных кузов и других. Как правило, на борту одного судна перевозится одновременно большое число партий. Ведущие позиции в мировой торговле в этом направлении занимает вертикальная система обработки судов с контейнерами, хотя за последние годы широко реализуются накатные технологии [7].

Мировая контейнерная ТТС завершает технологическую перестройку, связанную с открытием модернизированного Панамского канала. Технические параметры океанских контейнеровозов неуклонно увеличивают, ввиду новых предоставленных возможностей. В 2014 году был построен контейнеровоз вместимостью в 19,3 тыс. контейнеров двадцатифутового стандарта (дфэ). Уже заказаны и находятся в постройке контейнеровозы еще большей рекордной вместимости - до 22 тыс.дфэ.

Во всем мире происходит перестройка морских линий и специализированных терминалов. С учетом этих тенденций идет модернизация и на российском морском транспорте.

Крупнейший мировой судовладелец Maersk Line в 2011 году заключил контракт с южнокорейской фирмой Daewoo Industries на строительство 20 контейнеровозов класса Triple E-class вместимостью 18000 дфэ. на 2013-2016 годы. Кроме того, в ближайшие годы прогнозируется ввод в эксплуатацию еще 88 судов E-class, что по оценкам экспертов приведет к существенному обновлению флота, работающего на евро-азиатских линиях и переключению контейнеровозов меньших размеров вместимостью 600010000 дфэ. на порты США, большинство из которых в настоящее время способны принимать суда вместимостью не более 12000 дфэ. 
Себестоимость перевозки одного контейнера морем в межконтинентальных сообщениях на новом большегрузном флоте (расчетной вместимостью 16-20 тыс. дфэ) снизится примерно вдвое при сокращении срока доставки на 2-3 суток. Это подтверждается реальными данными по уже построенным первым крупным судам.

На российском морском транспорте идет модернизация, прежде всего, в части подготовки портов к приему крупнотоннажного флота. Так, 2013 год отмечен приемом на Дальнем Востоке первого крупного океанского контейнеровозов вместимостью 18,3 тыс. дфэ. В июле 2013 года контейнеровоз Maersk McKinney Moller впервые был обработан в российском порту Восточный на терминале ВСК. Это судно компании Maersk имеет длину 399 м, ширину 59 м, высоту борта - 73 м.

На сегодняшний день дальневосточный терминал ВСК - единственный, который получил разрешение на обработку контейнеровозов этого класса. Ведь при ширине судна 59 м необходимо иметь и береговые контейнерные перегружатели с соответствующим большим вылетом на консоли. Для приема контейнеровозов, параметры которых соответствуют потребностям мировой контейнерной системы, на терминале и в порту была проведена значительная работа по модернизации. Во второй половине 2013 года судо-заходы контейнеровозов вместимостью порядка 18 тыс. дфэ стали регулярными.

В начале 2015 года в российском порту Посьет на Дальнем Востоке был обработан самый крупный контейнеровоз в мире MSC Oscar. Длина этого судна - 395 м, ширина - 59 м, контейнеровместимость 19224 дфэ. Контейнеровоз MSC Oscar был принят в строй в начале 2015 года и стал крупнейшим судном данного типа в мире.

На Черном море контейнеровозы вместимостью по 5000 дфэ. будут заходить теперь в Новороссийск также регулярно. ZIM Integrated Shipping также увеличивает вместимость своего флота, занятого на черноморском сервисе линии ЕMX. С июня 2009 начата плановая замена группы судов вместимостью 4250 дфэ на суда вместимостью 5000 дфэ.

Первое судно вместимостью 5013 ед. в Новороссийском порту было обработано в июле 2009 г. Контейнеровоз «ZIM Barselona» стал крупнейшим судном для перевозки контейнеров, зашедшим в порт Новороссийска. Длина судна - 294 м, ширина 32 м.

В порту Усть-Луга вошла в эксплуатацию первая очередь специализированного контейнерного терминала. Строительство «Усть-Лужского контейнерного терминала» ведется в 3 очереди. Первая очередь введена в начале 2012 года. После реализации всего проекта его пропускная способность к 2025 году достигнет 3 млн. дфэ.

Весомое снижение себестоимости океанских перевозок явилось основой расширения перевозок насыпных и навалочных грузов в контейнерах серии ИСО. Прежде всего, это относится к внешнеторговым перевозкам партий указанных грузов, размер которых менее вместимости одного трюма типичного судна-навалочника, работающего на данном направлении перевозок. Наиболее характерными позициями являются промышленные сырьевые грузы, такие как шамотные материалы, шлакообразующие, стальной лом, раскислители, ингибиторы и катализаторы технологических процессов в металлургии, стекольной и химической промышленности, которые нужны производству в объемах, соизмеримых с вместимостью одного или группы крупнотоннажных контейнеров (т. Е. 10-1000 тонн), в отличии от основного сырья, потребляемого крупными производствами годовыми объемами в сотни тысяч тонн и более [8].

Во-вторых, переход на контейнерные отправки целесообразен в тех случаях, когда необходим контроль за продвижением партии груза в процессе перевозки и доставка «точно в срок» [9]. В частности, это касается ряда новых производств, таких как сталелитейные мини-заводы, которые в соответствии с принципами современной логистики не имеют крупных складов и копровых цехов, а получают все составляющие для своего производства «с колес» и вовремя [10]. Подобные транспортно логистические системы все активнее внедряются и подтверждают свою эффективность более высокими экономическими показателями [11].

Кроме того, российский экспорт носит преимущественно сырьевую направленность [12]. По статистике объемы перевозок грузов в контейнерах морем в импорте превышают объемы в экспорте в 1,7-1,8 раза. Контейнеризация экспортного грузопотока сырьевых грузов позволяет снизить объемы перевозок порожних универсальных контейнеров и сократить транспортные издержки [13].

Исторически первой является перевозка насыпного, навалочного груза, предварительно затаренного в мешки, полиэтиленовые упаковки или иную первичную тару. Однако суммарная стоимость такой первичной тары, отнесенная на единицу массы перевозимого груза, значительна. И в современных условиях данная традиционная технология может быть рекомендована, если покупатель в дальнейшем намерен распродать товар по частям конечным потребителям [14] .

Для погрузки навалочных грузов по традиционной технологии контейнер устанавливают горизонтально и загружают его ковшовым колесным погрузчиком типа Bob Cat, грузоподъемностью 0,51,5 т. По габаритным параметрам погрузчик должен входить в проем контейнера, а осевая нагрузка - 
соответствовать допускаемой нагрузке используемых контейнеров. При расположении контейнера горизонтально заполнить его внутренний объем полностью до верха и у дверей не удается [15].

В международной торговле отмечается рост контейнерных перевозок насыпных, навалочных грузов с применением технологии контейнерных вкладышей, а также непосредственно навалом, с погрузкой в предварительно скантованные вертикально крытые универсальные контейнеры [16].

При перевозке насыпных грузов в дверном проеме контейнера приходится устанавливать, как правило, одноразовые щиты, которые при экспортных перевозках не возвращаются отправителю, а стоимость материалов на их изготовление (доски, гвозди, полиэтиленовая пленка и др.) целиком ложится на расходы по грузоперевозке. Ввиду этого все шире используется конструкция полимерного вкладного вкладыша, внутри которого помещены дополнительные продольные синтетические стропы [17]. После засыпки груза вкладыш приобретает форму внутреннего пространства контейнера, при этом он зацепляется за гофры контейнера. После загрузки рабочему достаточно затянуть стропы на кармане со стороны входной двери и скрепить их с продольными внутренними стропами. Такая конструкция позволяет осуществлять безопасную контейнерную перевозку без щита в проеме. Что апробировано в межпортовом и автомобильно-морском сообщениях. Использование этого наиболее прогрессивного варианта при железнодорожных перевозках находится сейчас в стадии апробации.

При загрузке в контейнер, установленный горизонтально, насыпного или навалочного груза удается заполнить не более 90-92 \% его объема. Лучшее заполнение достигается, если контейнер при погрузке предварительно устанавливают вертикально [18]. Для этих целей используется специализированное оборудование - контейнерные кантователи с гидравлическим приводом [19].

Недостаток свободных площадей для развития морских терминалов в портах России явился причиной формирования «сухих портов» - отдаленных от основной территории и береговой черты территорий порта, на которых осуществляется складирование и обработка контейнерных грузов [20]. Как правило, при «сухих портах» формируются логистические центры, оказывающие грузовладельцам более широкий спектр услуг по подготовке грузов к перевозке, пакетизации, таможенному режиму.

Несмотря на трудности современной ситуации, в 2016 году ожидается активизация морских перевозок навалочных и насыпных грузов в крупнотоннажных контейнерах через порты России, а также дальнейший рост общих объемов контейнерных перевозок.

\section{Лumepamypa}

1. Гагарский Э. А. Прогрессивные транспортно-технологические системы: трудности роста // Морской флот. 2009. № 3. С. 3.

2. Елисеев С. Ю., Тучков Э. В., Куренков П. В. Логистика в управлении внешнеторговыми перевозками // Экономика железных дорог. 2005. № 7. С. 28-31.

3. Давыдов Г. Е. Реформирование железнодорожного транспорта: итоги и проблемы // Менеджмент и бизнес-администрирование. 2008. № 4. С. 66-76.

4. Резер С. М., Москвичев О.В. Состояние методического базиса технического и технологического развития контейнерных перевозок в России // Транспорт: наука, техника, управление. 2015. № 3. С. 12-14.

5. Гагарский Э. А., Кириченко С. А., Козлов С. Г. Транспортное обеспечение добычи углеводородов в прибрежных и шельфовых месторождениях Ямала - актуальная проблема современного развития нефтегазовой отрасли // Транспорт: наука, техника, управление. 2016. № 5. С. 46-53.

6. Гагарский Э. А., Кириченко С. А., Поляниев Ю. Д., Дугин Г. С. Укрупненные грузовые единицы в транспортно-технологических системах - главный фактор энергоэффективного развития транспорта // Транспорт: наука, техника, управление. 2015. № 1. С. 68-70.

7. Гагарский Э., Кириченко С. Новое в развитии накатных технологий // Морской флот. 2007. № 2. С. 37 42.

8. Гагарский Э. А., Кириченко С. А., Кириченко А. С. Развитие контейнерных перевозок лома // Бюллетень транспортной информации. 2009. № 2. С. 18-21.

9. Крутоног Л. Г. Аспекты формирования интегрированных логистических систем при организации внешнеторговых перевозок. Практика и тенденции // Транспорт: наука, техника, управление. 2015. № 5. C. 57-59.

10. Кириченко С. А., Кириченко А. С. Антикризисная контейнеризация // Вторичные металлы. 2009 . № 3. C. $70-72$.

11. Москвичев О.В., Никонов Ю. С. К вопросу повышения эффективности контейнерных перевозок // Транспорт Урала. 2009. № 4. С. 22-24.

12. Третьяков Г. М., Москвичев О.В., Никонов Ю. С. Актуальные аспекты развития контейнерных перевозок // Вестник транспорта Поволжья. 2012. № 3 (33). С. 26-29. 
13. Терёшина Н. П., Резер А. В. Повышение уровня контейнеризации и эффективности транспортнологистического комплекса // Железнодорожный транспорт. 2014. № 5. С. 28-31.

14. Москвичев О.В., Никонов Ю. С. Оценка потенциала и перспектив развития контейнерной транспортной системы // Железнодорожный транспорт. 2013. № 4. С. 37-39.

15. Гагарский Э. А., Кириченко С. А. Зарубежный и отечественный опыт перевозок наливных, насыпных и навалочных грузов в универсальных контейнерах на принципах логистики // Транспорт: наука, техника, управление. 2009. № 12. С. 26-29.

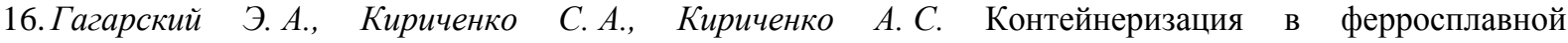
промышленности // Бюллетень транспортной информации. 2011. № 5. С. 3-6.

17. Кириченко С. А., Лахметкина Н. Ю. Мультимодальные контейнерные перевозки зерна // Мир транспорта. 2015. Т. 13. № 1 (56). С. 116-125.

18. Кириченко $A$. C., Сипаро K. А., Букин $A$. В. Экспорт черного лома и проблемы обеспечения морских перевозок // Вторичные металлы. 2014. № 5. С. 20-23.

19. Татарский Э. А., Кириченко С. А., Кириченко А. С. Логистические аспекты контейнеризации продукции ферросплавной промышленности // Интегрированная логистика. 2011. № 3. С. 27-30.

20. Гагарский Э. А., Толкачева М. М., Кириченко С. А. Развитие «сухих портов» - основа дальнейшего совершенствования взаимодействия различных видов транспорта // Бюллетень транспортной информации. 2013. № 10 (220). С. 003-007. 